\title{
The Influence of Romantic Culture of Chu on the Stone Picture of Han Dynasty in Nan yang
}

\author{
Lanzhen Wang \\ Huanghe Science and Technology College \\ Zhengzhou, China \\ e-mail: 405872257@qq.com
}

\begin{abstract}
This article is to analyze the artistic thoughts and language heritage of the Influence of the romantic and mythological culture of Chu on the Stone Picture of Han Dynasty in Nan yang, and to describe the visual illustration of the Stone Picture in Nan yang. It makes the conclusion that a people has both the history of words and visual illustration.
\end{abstract}

Keywords-Culture of Chu; the Stone Picture of Han Dynasty in Nan yang; visual illustration

Chu culture is bold and unrestrained, romantic and genuine feeling of ancient civilization symbol [1]. Chu culture is the pre-qin period a regional culture with a long history, is an important part of the ancient Chinese civilization, is one of the important basis and source of the han dynasty culture, also is the content of the visual image of Nanyang Han stone and forms an important part of. In the process of development and evolution, unceasingly absorb, digest from huaxia, wu yue, bashu culture, such as some good factors, gradually formed the permeated with romantic passion and vitality of the unique chu art: rich and strange shape WuFeng rich and mysterious; Feiyang smooth lines, wild romance; Colorful numerous rich, mysterious magnificent; Real emotional exposed unique artistic style, rich in abstract form aesthetic feeling, is the vivid artistic reflection of the relationship between man and nature.

\section{OF THE NANYANG HAN STONE VISUAL IMAGES ART ADITION}

\section{A. The Nanyang Han stone visual images art thoughts}

Chu culture, in time, it is with the development of the southern chu and mature. Says from the space, and with constant expansion of the spring and autumn period and the warring states period chu territory and spread to the general area. Chu culture has its own distinctive features, has a strong romantic emotional appeal and myth color, freedom, passion, good at imagination, good good dance song, but do good temple, heavy thick god wu, the flavor of the original culture is very strong. In quite a long period of history, people can't see it looks like. It was not until nearly a century of chu cultural relics unearthed continuously, make the people of chu art style of visual art and style, with strong and deep impression, see the ancient human mind and spirit of a kind of very unique art show.

Of art, chu art is an important part of chu culture, is the embodiment of people spirit, is a rarity in the jingchu land. Chu art features: first, it keeps the ChuMin plowed, trek in the original sense of recognizing things, and to conquer the world, the world of aesthetic mentality and connotation, become an important part of Chinese national art, mysterious WuFeng breath. Second, chu strangeness of folk customs, developed science and technology, craft boutique, chic style, all reflect the romantic color. Chu art has a romantic creation attitude, full of the passion of life, with the break through all resistance and heroism and confidence, and ration to make art.

\section{$B$. The Nanyang Han stone visual images art language}

Nanyang Han stone showed unique romantic, obviously has the characteristics of the art of chu culture. Fuxi nuwa of Nanyang Han stone first snake body, party's bulging eyes zheng, majesty horror of tu, yu lei, fierce beast steller antlers African a bear strong good, shows the original mysterious and wild.

As can be seen from the han in the grave fresco, feather fairy rise of the Taoism, wrote the song "rose fairy fantasia". Feather rose fairy fantasy also developed later, the beauty of the butterfly lovers into butterflies fly. Rise as an immortal on the familiar "fantasia", unlike zhuangzi type personality spirit of independence and freedom, and the alienation of official at that time. Han stone to civilian positions reflect the secular elite, pass feather rose fairy art pattern, showing an unprecedented cultural pattern of "happiness" of the han dynasty. The dead soul ascend to heaven, means the harmony of the earth, the living in various sacrificial ceremony, is conducive to harmony among them into the earth. Therefore, although han is primarily used to create illusion, performance fairyland, but through a lot of figure painting instead of shanshui landscape, more direct, more effectively put the han nationality deep psychological activities on the rocks.

Nanyang has a long history, the history of nanyang is penetration at the forefront of the pre-qin culture to south, from the warring states period, chu art is origin of quality, unique artistic technique of expression, and recreates the han dynasty such as the political, economic, ideological, cultural and arts in the field of space, with the development of The Times and development to create many immortal works, nanyang and therefore the important base of the han dynasty stone. Nanyang is the birthplace of chu culture, nanyang in 
the dividing line between north and south culture, the cultural impact and integration, has created prosperity and unique culture of nanyang. Nanyang Han stone the visual image of both the central plains people overlooking the loess land, there is also a way of deep blue sky. It is because of the combination of the two kinds of visual, nanyang expand the horizons, Nanyang Han stone broad visual images reflect regional and local characteristics.

Nanyang stone of visual images under the strong influence of chu culture, highlight the animals and the mythological and formed a "slightly rough" lu xun said, bold and unrestrained powerful, the composition of the artistic style of shu lang type [2]; Shandong stone express Confucian moral ideal historical stories, form is austere, layout and intensive artistic style [3]; Shaanxi han stone in real life as the theme, there are more of farming, hunting, animal husbandry, historical themes uncommon, myth, simple and flat object the artistic style of painting, plain and concise adornment sex is strong, it can be seen that the influence of qin culture and $\mathrm{Hu}$ Wenhua [4]. Sichuan han stone sarcophagus, is not only the deployment of special performance, local culture and the concentration of the central plains han tomb stone [5], and the central plains han tomb stone is sichuan han portrait sarcophagus.

\section{OF THE NANYANG HAN STONE VISUAL IMAGE REFERENCE METHOD}

\section{A. the Nanyang Han stone visual elements of visual images}

Nanyang Han stone visual elements of visual image is point, line, face, through comprehensive constitute elements of dot, line, face, make these pictures images can be an image, also can be two or more image, the image gives thoughts and feelings; In the visual art and painting art middle point, line, face, etc on the use of visual elements bring us visual sense of beauty to enjoy, the message; Dot is the most concise element, a line is moving trajectory, face is the line moving trajectory, and intensive can form a line and point movement. Said here is mainly the use of a rolled off the production line, line is the basic elements of plastic arts, the combination of line and line freedom, generalize, visual image of each line is a full of vitality, linear, horizontal line, curve and broken line to give different visual feelings; Straight to the grave, strength, strong feeling, give a person the feeling of peace and serene, horizontal curves give a person the feeling, beautiful, gentle, flow line gives a person the feeling, rush about, and forward the rhythm feeling of line due to the s, stone, carving techniques and subject matter content is different, make the line slightly different rhythm. Line model is the first to use human means of art form, the ingenious combination of line and line of Nanyang Han stone in contrast and conflict get harmonious aesthetic feeling, full of vitality, the line into the emotion. Using the elements of visual art creation, increase the image movement and dynamics, this is the value of Nanyang Han stone visual image. It can be a nutshell Nanyang Han stone of the line in the visual image is an artist known as the most beautiful line.

Gestalt psychologist said: "people's eyes tend to see any kind of stimulation patterns as the known conditions to achieve the most simple shapes [6]" han stone by the visual elements of dot, line, face a single image, the image of a single form the visual images, the combination of image and image to create the art of visual and auditory synaesthesia, picture presents the rhythm and rhyme, stimulate synaesthesia sense the beauty of han stone depicting images, the visual image of contour lines of the Nanyang Han stone change multiterminal, line is fluent, uninhibited, open freely. Nanyang Han stone

\section{B. Visual image of the color relations}

Color is the most abstract language. As a symbol of emotion and culture, in the design, not only has the aesthetic and decorative, also has symbolic significance [7]. Nanyang Han stone visual image is black with white color relations, black and white are the two color, color is called on learning without color. Nanyang Han stone expression is not the object size, forming a kind of black and white and dichromatic constitute a visual image, protruding and concave bottom, image according to the needs of black and white layout arrangement design, as the white paper on ink image, lao-tzu: is known by its white, keep the black, which means to grasp the essence of the universe is full of movement, the black to white, Bai Zhongyou black, black with white, is based on the nature of the dark will pay more attention to the change of the white, In the modern design and color in a painting, reality in black, white is virtual, black and white are opposites, the relationship between black and white is a color of the eternal. Black and white like the feeling of Yin and Yang, the black soul is white, white to the extreme is black.

Black and white give a visual with clear signal, let a person feel brimmed black, white, let a person feel empty net. Black is one of the people are used to determine something external contour medium, its itself is without excitant; White is between light and visual media, is satisfies the requirement of vision or physiological condition, so when we face white single, accustomed to it as a transparent or space. With our eyes open, the improvement of aesthetic taste, many families also break through the bondage of the understanding of traditional color boldly adopted the black and the mass-tone attune of the play is tie-in, embodies the distinctive design style and modern breath.

\section{C. visual image of Nanyang Han stone picture layout composition}

Nanyang Han stone images of the visual image of shu lang layout, prominent, distinctive thematic compositions for a stone a theme, created the Chinese painting alone, in "a stone a theme" is commonly used in painting art form of composition. Topic content repeat life into the art of romantic emotional appeal, on the basis of the is the perfect combination of realism and romanticism. Nanyang Han stone images of the visual image of the layout change and unity, and take care of the overall relationship between free when combined with the use of lines, composition layout a balanced composition. 
Composition is an artist to show a certain thought, artistic conception, emotion, in a certain range of space, use the principle of aesthetic arrangement and image processing, the location of the symbol, for their persuasive art as a whole. Nanyang Han stone composition method of visual images, far down near a scatter perspective on composition method become the standard of Chinese painting perspective composition pattern, although do not conform to the natural true perspective method, but in line with people's aesthetic habits, this way of composition of a picture from the fetters of natural view and the limitation of time and space, put the direct object clearly shown; To fill the white picture blank processing usually adopt way, namely in the picture the main object of blank place, with the birds and animals and trees, such as moire filling. Fill in the white is a main composition of medieval art. Here said the "fill in white" is borrowed from han dynasty after the formation of the theory of painting language. Nanyang Han stone to fill in the visual image of the white, is an integral part of the picture content, have the function of the foil picture content body. Fill in white birds, such as horses and chariots, travel the picture more foil a neatly and rapidly marching motor. In gods, fairy, strange beast different birds such as stone picture fill compose change flowing clouds form lines, increase the ethereal picture clever feeling. This kind of fill white composition, make the picture is balanced abound change, showing a full enrichment of artistic conception.

Nanyang Han stone of visual images is to create the image of the han dynasty in nanyang spirit, is the han dynasty stone art is an important part of. Society in constant progress, we in reference on the basis of good at learning, good at innovation, good at summarizing and eclecticism.

\section{CONCLUSION}

Nanyang Han stone visual image acquisition of heaven and earth reiki, condensation of human MUSES, using simple language to depict real life. Like Nanyang Han stone not only made use of the advantages of art and artistic features, incisively and vividly convey the connotation of the works of art, that is, condensed the confused things to refine, real intuitive expression comes out, can not replace other art. "The immortal works appeared not only exists in the history of the production process, also from the process of human aesthetic activities, to participate in the interaction of two process with a new attitude, to the life of the past and present of the dialogue to continue work, it is the role of han stone aesthetics research [8]".

\section{REFERENCES}

[1] Xia Jin. Chu culture symbolic language of modern design semantic expression analysis [J]. Journal of packaging engineering, 2009, 30 (12) : 210-212

[2] Wang Xiaozhu. Henan han dynasty portrait study [M] zhongzhou ancient books publishing house, 1996.

[3] Li Falin. Shandong han stone research [M]. Qilu publishing house. 1986.

[4] Shaanxi shenmu dabao when han stone coloured drawing or pattern [M]. Chongqing publishing house, 1998. Gawain
[5]. Sichuan han dynasty portrait sarcophagus set [M]. People's fine arts publishing house, 1984.

[6] Chen Zhenwang. Symbol consumption society of packaging design semantics analysis [J]. Journal of packaging engineering, 2007, 28 (1) : 122-124. Rudolf arne haim.

[7] Visual perception and art [M]. China social sciences press, 1984:64. Et al.

[8] Aesthetic thinking of the han stone [M]. 1991. 